SLAC-PUB-8085

March 1999

\title{
ENVIRONMENTAL IMPACT FROM ACCELERATOR OPERATION AT SLAC*
}

\author{
James C. Liu, A. Fasso, S. Mao, W. R. Nelson, R. Seefred and R. Sit \\ Stanford Linear Accelerator Center \\ MS 48, P.O. Box 4349, Stanford, CA 94309, USA \\ E-mail of Corresponding Author: james@ slac.stanford.edu
}

\begin{abstract}
Environmental impacts from electron accelerator operations at the Stanford Linear Accelerator Center, which is located near populated areas, are illustrated by using examples of three different accelerator facilities: the low power (a few watts) SSRL, the high power (a few kilowatts) PEP-II, and the 50-kW SLC. Three types of major impacts are discussed: 1) off-site doses from skyshine radiation, mainly neutrons, 2) off-site doses from radioactive air emission, mainly ${ }^{13} \mathrm{~N}$, and 3) radioactivities, mainly ${ }^{3} \mathrm{H}$, produced in the groundwater. It was found that, from SSRL operation, the skyshine radiation result in a MEI (Maximum Exposed Individual) of $0.3 \mu \mathrm{Sv} / \mathrm{y}$ while a conservative calculation using CAP88 showed a MEI of $0.36 \mu \mathrm{Sv} / \mathrm{y}$ from radioactive air releases. The calculated MEI doses due to future PEP-II operation are $30 \mu \mathrm{Sv} / \mathrm{y}$ from skyshine radiation and $2 \mu \mathrm{Sv} / \mathrm{y}$ from air releases. The population doses due to radioactive air emission are 0.5 person-mSv from SSRL and 12 person-mSv from PEP-II. Because of the stronger decrease of skyshine dose as the distance increases, the population dose from skyshine radiation are smaller than that from air release. The third environmental impact, tritium activity produced in the groundwater, was also demonstrated to be acceptable from both the well water measurements and the FLUKA calculations for the worst case of the SLC high-power dump.
\end{abstract}

Invited talk presented at the

1999 Symposium on Environmental Radiation Monitoring Technology,

Kaohsiung, Taiwan, March 18-19, 1999

* Work supported by the Department of Energy under contract DE-A-03-76SF00515 


\section{INTRODUCTION}

The study of, and the development of tools to evaluate, the environmental impacts from accelerator operations has become more important as the public concern over radiation exposure increases. The major environmental impacts from accelerator operations may include the following: 1) off-site doses to the public from either skyshine radiation or airborne radioisotopes produced and released into the environment, and 2) radioactivities produced in the groundwater environment.

Stanford Linear Accelerator Center (SLAC) is located near areas that are densely populated. SLAC operates several electron accelerator facilities, which differ in beam parameters, facility and shielding configurations, and operating schedules. Therefore, the environmental impacts due to the operation of these accelerators will also be different.

This paper illustrates the environmental impacts from three electron accelerator facilities at SLAC: the low-power SSRL, the high-power PEP-II, and the $50-\mathrm{kW}$ SLC. The impacts, evaluated using both calculations and/or measurements, are presented in the following order:

1) Off-site doses from skyshine radiation (dominated by neutrons),

2) Off-site doses from radioactive air emission (mainly from ${ }^{13} \mathrm{~N},{ }^{15} \mathrm{O}$, etc.), and

3) Radioactivities (mainly ${ }^{3} \mathrm{H}$ ) produced in the groundwater.

Figure 1 summarizes the environmental radiological protection scheme at SLAC. The main regulatory basis for the environmental monitoring program is DOE5400.5 ${ }^{1}$, which is to be superceded by $10 \mathrm{CFR} 834^{2}$ in the near future. The three major pathways (direct, air and water), the respective contributing sources, the governing regulation used for each source ${ }^{1-6}$, and related legal limits are all shown in the figure.

\section{ACCELERATOR FACILITIES AND MONITORING PROGRAM}

Figure 2 shows a major part of the SLAC. The 2-mile-long LINAC (only the last sector is shown on the west) provides electron beams at various energies and powers to several accelerator facilities (e.g., PEP-II, SLC and ESA shown). The nearest boundary where there is continuous occupancy by members of public is by the Sand Hill Road (400 m north to the SSRL).

SSRL is an independent facility. It is like one of the many synchrotron radiation accelerator facilities in the world, whose injection beams run generally at a few watts and a few GeV level. SSRL consists of an injector (150-MeV Linac and $2.3 \mathrm{GeV}$ Booster ring) and a $2.3 \mathrm{GeV}$ storage ring. The whole facility is above ground and has relatively thin shielding (1-4 feet of concrete). The major 
environmental impact is the off-site doses due to skyshine and air emission, with the main source being the beam losses during daily injections into the storage ring.

The high power PEP-II is a large storage ring of 2200-m-circumference currently under commissioning. Most of the tunnel ring is at least 5-m underground except the five Interaction Regions (IR), in which the roof is only 4' thick concrete. In IR8, the injection beam of $\sim 1$ kilowatt in top-off mode will produce the highest off-site doses from skyshine and air emission for future PEP-II operation.

On the other hand, the SLC collider tunnel is totally underground and, in this case, the environmental impact is different form the SSRL and PEP-II. The major beam loss points are the electron and positron beam dumps ( $20 \mathrm{~m}$ deep) receiving $50-\mathrm{kW}$ beams almost continuously. Therefore, it is the potential induced activities (particularly ${ }^{3} \mathrm{H}$ ) in the groundwater near the dumps that are of major environmental concern.

Figure 2 also shows the locations of the active (PMS) and passive (TLDs) radiation monitoring stations used to measure the boundary doses from skyshine radiation. As an independent verification, the State of California also conducts environmental dose monitoring at SLAC using $\mathrm{CaSO}_{4}$ TLDs. Air Monitoring Stations (AMS) and Waste Water Monitoring Stations (WWMS) are also installed in strategic locations to confirm that the amounts of radioactive air and water releases to the environment are below regulatory limits ${ }^{7}$.

\section{SKYSHINE RADIATION}

Among the sources contributing off-site doses to the boundary of a high energy accelerator facility, skyshine radiation is generally the dominant one. The skyshine dose is clearly a function of beam loss conditions (beam particle, energy, power, target), shielding conditions (in particular, the roof material and thickness), and the distance between beam loss point and the boundary.

Dose rate measurements for skyshine neutrons and photons have been made for three cases of controlled beam loss at SSRL and PEP-II. The example shown here is the SSRL electron beam $(2.3 \mathrm{GeV}, 2 \mathrm{~W})$ hitting a lead Faraday cup $(0.6 \mathrm{~m}$ below a 61-cm-thick concrete roof) in the injection line into storage ring. Neutron detectors used were moderated $\mathrm{BF}_{3}$ fluence detectors and Anderson-Braun ${ }^{3} \mathrm{He}$ remmeters, while photon measurements were made with sensitive GM detectors ${ }^{8}$.

Compared to the high natural background $(\sim 50 \mathrm{nSv} / \mathrm{h})$, small amounts of skyshine photons could not be measured easily. Because of the high attenuation of photons in shielding and the low scattering of photons in air, the dose from skyshine photon should only be a faction of the skyshine neutron. 
The measured signal ratios between fluence detector and remmeter at SSRL and PEP-II indicated that the skyshine neutrons have an average energy between 0.5-1 MeV. Using the conservative value of $1 \mathrm{MeV}$ for detector sensitivity, the skyshine neutron dose rate from SSRL beam parked in Faraday cup, measured by the moderated $\mathrm{BF}_{3}$ detector, is plotted as a function of distance up to $400 \mathrm{~m}$ in Figure 3. Skyshine neutron dose rates were also calculated using the analytic SKYSHINE code ${ }^{9}$. In the case of SSRL a good agreement can be seen in Figure 3, which gives a skyshine neutron of $0.7 \mathrm{nSv} / \mathrm{h}$ at $380 \mathrm{~m}$ for $1-\mathrm{W}$ beam parked in Faraday cup. Note that the natural neutron background is around $4 \mathrm{nSv} / \mathrm{h}$.

Figure 4 plots the skyshine neutron signals of PMS1, $250 \mathrm{~m}$ away from SSRL, during the second half of 1998. Most signal spikes were due to beam losses during normal and machine-physics injections. From the net integrated signal, the annual skyshine dose from SSRL operation is estimated to be $1.1 \mu \mathrm{Sv} / \mathrm{y}$ at PMS1, assuming that both the operation and occupancy periods are $7200 \mathrm{~h} / \mathrm{y}$.

When the results in Figure 3 are fitted with the well-known Lindenbaum skyshine formula ${ }^{10-11}$ (i.e., the inverse square law plus an exponential term with an attenuation length of $\lambda$ ), the $\lambda$ value is obtained as $500 \mathrm{~m}$ over the distance studied. Our $\lambda$ value agrees with others ${ }^{11-13}$. From the above PMS1 annual dose and the fitted skyshine formula, the SSRL skyshine neutrons would result in a MEI (Maximally-Exposed Individuals) of $0.3 \mu \mathrm{Sv} / \mathrm{y}$ at $400 \mathrm{~m}$ away, next to Sand Hill Road.

Figure 5 shows the off-site dose map (for year 1998) up to $8 \mathrm{~km}$ away from SLAC due to SSRL skyshine neutrons. The skyshine neutron dose is directionally independent in this case. The numbers below the city names are the city's population (in units of thousands) from the US 1990 census data.

The annual off-site doses from skyshine neutrons due to future PEP-II operation were calculated using the SKYSHINE code, based on the estimated annual beam loss parameters. It was found that a maximum individual dose of 30 $\mu \mathrm{Sv} / \mathrm{y}$ occurs at the horse track, $60 \mathrm{~m}$ south of IR6, if it is occupied 7200 hours per year.

There are no legal limits set specifically for the skyshine dose, but SLAC has an internal limit for shielding design that the skyshine should not contribute more than $100 \mu \mathrm{Sv} / \mathrm{y}$. The skyshine doses estimated for SSRL and PEP-II are much less than the SLAC internal limit.

\section{RADIOACTIVE AIR EMISSION}

The main airborne radionuclides come from the bremsstrahlung-induced spallation products in air $\left({ }^{11} \mathrm{C},{ }^{13} \mathrm{~N},{ }^{15} \mathrm{O}\right)$ and the argon gas activated by thermal 
neutrons $\left({ }^{41} \mathrm{Ar}\right){ }^{14}$. Table 1 summarizes the estimated annual releases (in GBq/y) of radionuclides, as well as the dose impacts, to the environment due to PEP-II and SSRL operations. These were calculated based on similar annual beam loss parameters used in the estimation of skyshine radiation. At SLAC the ventilation is normally turned off during accelerator operation for machine performance reasons. However, there are many unsealed penetrations and holes throughout the accelerator tunnels or rings, and it is difficult to estimate the actual air release rates. Optimum targets which generate maximum yields of radionuclides and one full air change per hour (i.e., one release of saturated activities, except ${ }^{41} \mathrm{Ar}$, per hour, and $7200 \mathrm{~h} / \mathrm{y}$ ) were conservatively used in the calculations. With the annual activities released, meteorological data, and population distribution up to $80 \mathrm{~km}$ from SLAC, the CAP88 code ${ }^{15}$ was then used to calculate the MEI dose and the collective dose $(\mathrm{Hc})$.

The calculated results in Table 1 show that nitrogen-13 dominates the activity release and dose contributions (over 50\%). The MEI dose is $2 \mu \mathrm{Sv} / \mathrm{y}$ from PEP-II and $0.36 \mu \mathrm{Sv} / \mathrm{y}$ from SSRL, much less than the NESHAPS legal limit of $100 \mu \mathrm{Sv} / \mathrm{y}^{3}$. The collective dose is 12 person-mSv from PEP-II and 0.5 person$\mathrm{mSv}$ from SSRL. Because of the difference in the accelerator's operating power, the collective dose from PEP-II are at least twenty times higher than the SSRL.

Figure 6 shows the CAP88-calculated annual dose map from PEP-II operation. Because of the wind direction and speed, the maximum doses occur in the ESE direction; however, the MEI dose of $2 \mu \mathrm{Sv} / \mathrm{y}$ remains on the north due to the continuous occupancy there.

Note that the dose as a function of distance from air emission does not drop as fast as that from skyshine. For example, the skyshine dose from SSRL at $8 \mathrm{~km}$ $\left(\sim 10^{-8} \mu \mathrm{Sv} / \mathrm{y}\right)$ is comparable to its air emission dose at $50 \mathrm{~km}$.

\section{TRITIUM IN GROUNDWATER AND WASTE WATER}

Figure 7 shows the north-south cut along the SLC beam line. The 50-kW electron and positron beams, after passing through the interaction point (IP), are parked continuously on the south and north beam dumps (SFFD and NFFD), respectively. The dumps are at least $20 \mathrm{~m}$ below ground and $10 \mathrm{~m}$ above the estimated water table, in which water flows to the San Francisquito Creek a few hundreds meters away.

Figure 8 shows the vault of South Final Focus Dump (SFFD) for the electron beam. The water-cooled dump consists of thick aluminum and iron blocks. Therefore, tritium is produced in water of the soil around the dump from oxygen spallation mainly by high energy neutrons leaking out of the dump. The resulting 
maximum tritium saturation activity, calculated using FLUKA code ${ }^{16}$, was 4100 $\mathrm{Bq} / \mathrm{ml}^{17}$, which occurs near the surface of the soil. The FLUKA result also agrees (within a factor of ten) with analytic estimation and a soil sample measurement.

Before a comparison can be made with the EPA limit for the drinking water $(0.74 \mathrm{~Bq} / \mathrm{ml} \text {, which produces a dose of } 10 \mu \mathrm{Sv} / \mathrm{y})^{4}$, there are additional three activity reduction factors that need to be considered. They are the actual water amount in the soil, water migration to the water table, and the dilution of tritium activity in the water table before reaching any private well or the creek. However, these factors, albeit believed to be large enough to reduce the activity to insignificant levels, are difficult to estimate. Therefore, in addition to ten old wells (labeled SLC-x in Figure 7), two new wells MW-56 and MW-57 were installed recently between the dumps ( $10 \mathrm{~m}$ away) and the water table to monitor the potential tritium activity moved from the soil near the dumps to the water table. So far all water sample measurements in the new wells showed tritium activity below the detection limit of $0.0074 \mathrm{~Bq} / \mathrm{ml}$.

Another issue of tritium is that the California Code of Regulation ${ }^{5}$ requests that the annual release of tritium into the sewer system be less than $185 \mathrm{GBq} / \mathrm{y}$. At SLAC, the major source of tritium to sewer is the LCW (low conductivity water) cooling beamline components. Prior to the releases of LCW into the sewer, samples were taken and tritium activity measured. The measured tritium radioactivity in the LCW releases since 1992 is summarized in Table 2, which shows that SSRL contributed only a very small faction of total tritium activity from SLAC and the total annual tritium release has been well below the legal limit.

In addition, SLAC has only two main discharge points for industrial waste water into the local sewer system (see the two FMS in Figure 2). Composite sample monitoring has also been made in every FMS and no measurable tritium activity has been found.

\section{CONCLUSIONS}

The environmental impacts from accelerator operations at SLAC have been shown, with measurements and calculations, to be minimal using facilities of SSRL, PEP-II and SLC. The MEI doses from skyshine neutrons and radioactive air emission due to SSRL operation are about $0.3 \mu \mathrm{Sv} / \mathrm{y}$. Due to its higher power or a closer distance to boundary (in case of skyshine), PEP-II contributes the skyshine and air-emission doses that are a factor of 10-100 times higher than SSRL. In any case, they are still below the corresponding legal limits. Although conservative calculations indicated the worst case of SLC dump has a high tritium activity in the surrounding soil, actual measurements showed that no tritium activity has been released into the water table and, thus, no impact on the drinking water. 


\section{REFERENCES}

1. USDOE, Radiation Protection of the Public and the Environment, DOE Order 5400.5 (1990).

2. 10CFR834, Radiation Protection of the Public and the Environment, Proposed Rule, Code of Federal Regulation (1998).

3. 40CFR61, National Standards for the Emission of Radionuclides Other Than Radon from Department of Energy Facilities (NESHAPS), Code of Federal Regulation, Subpart H (1989).

4. 40CFR141, National Primary Drinking Water Regulation (NPDWR), Environmental Protection Agency (1992)

5. California Code of Regulation (CCR), Title 17, Public Health, Division 1, Chapter 5, Subchapter 4, Group 3, Article 5, Section 30287 (1994).

6. 40CFR122, National Pollutant Discharge Elimination Systems (NPDES), Code of Federal Regulation (1987).

7. SLAC, 1997 Site Environmental Report January-December 1997, SLAC-R525, SLAC, Stanford, CA 94309 (1998).

8. J. C. Liu, R. Seefred, and R. Sit, "Calibration summary of neutron sources and neutron detectors", SLAC-RP-98-3, SLAC, Stanford, CA (1998).

9. T. Jenkins, SKYSHINE Code, SLAC, Stanford, CA 94309 (1989)

10. S. J. Lindenbaum, "Shielding of high energy accelerators", Annu. Rev. Nucl. Sci. 11, p213 (1961).

11. G. R. Stevenson and R. H. Thomas, "A simple procedure for the estimation of neutron skyshine from proton accelerator”, Health Phys., 46(1), p115 (1984).

12. Y. Uwamino and T. Nakamura, "Three-dimensional neutron dose distribution in the environment around a $1-\mathrm{GeV}$ electron synchrotron facility at INS", Particle Accelerator, 21, p157 (1987).

13. G. Stapleton, K. O'Brien, and R. H. Thomas, "Accelerator skyshine: tyger tyger burning bright", Particle Accelerators, 44, p1 (1994).

14. IAEA, Radiological Safety Aspects of the Operation of Electron Accelerators, International Atomic Energy Agency, Vienna, IAEA Report 188 (1979).

15. B. Parks, CAP88 PC Code (Version 2), US Department of Energy, Germantown, MD (1997).

16. A. Fasso, A. Ferrari, J. Ranft, and P. R. Sala, FLUKA: Present Status and Future Developments, Proc. IV Int. Conf. On Calorimetry in High Energy Physics, La Biodola, Italy, 21-26, Sept., World Scientific, p.493 (1993).

17. W. R. Nelson, A. Fasso, R. Sit and S. N. Witebsky, Estimate of Tritium Production in Ground Water Near SLC Beam Dumps, SLAC, RP-98-2 Rev. (1998). 
Table 1. Calculated annual releases of radioactive air, as well as the dose impacts, to the environment due to PEP-II and SSRL operations.

\begin{tabular}{|c|c|c|c|c|c|}
\hline \multirow[b]{2}{*}{ Isotope } & \multirow{2}{*}{$\begin{array}{l}\text { Half-Life } \\
\quad(\min )\end{array}$} & \multicolumn{2}{|c|}{ PEP-II } & \multicolumn{2}{|c|}{ SSRL } \\
\hline & & GBq/y & Dose $(\%)$ & $\mathrm{GBq} / \mathrm{y}$ & Dose $(\%)$ \\
\hline${ }^{11} \mathrm{C}$ & 20 & 370 & 5 & 30 & 8 \\
\hline${ }^{13} \mathrm{~N}$ & 10 & 4400 & 60 & 170 & 56 \\
\hline${ }^{15} \mathrm{O}$ & 2 & 2200 & 20 & 90 & 28 \\
\hline${ }^{41} \mathrm{Ar}$ & 108 & 740 & 15 & 20 & 8 \\
\hline \multicolumn{2}{|c|}{ MEI Dose $(\mu \mathrm{Sv} / \mathrm{y})^{*}$} & \multicolumn{2}{|c|}{2} & \multicolumn{2}{|c|}{0.36} \\
\hline \multicolumn{2}{|c|}{ Hc (person-mSv) } & \multicolumn{2}{|c|}{12} & \multicolumn{2}{|c|}{0.5} \\
\hline
\end{tabular}

* NESHAPS legal limit: $100 \mu$ Sv/y.

Table 2. Measured annual releases of tritium radioactivity (in $\mathrm{GBq} / \mathrm{y}$ ) in LCW (low conductivity water) released into sewer system *.

\begin{tabular}{ccc}
\hline Year & SLAC & SSRL \\
\hline 1992 & 1.5 & --- \\
1993 & 0.1 & --- \\
1994 & 0.07 & --- \\
1995 & 0.4 & 0.001 \\
1996 & 12.5 & 0.001 \\
1997 & 0.8 & 0.00004 \\
1998 & --- & 0.00007 \\
\hline
\end{tabular}

- Limit is $185 \mathrm{GBq} / \mathrm{y}$ from CCR Title 17. 


\section{Environmental Radiological Protection at SLAC \\ (DOE 5400.5, 10CFR834)}

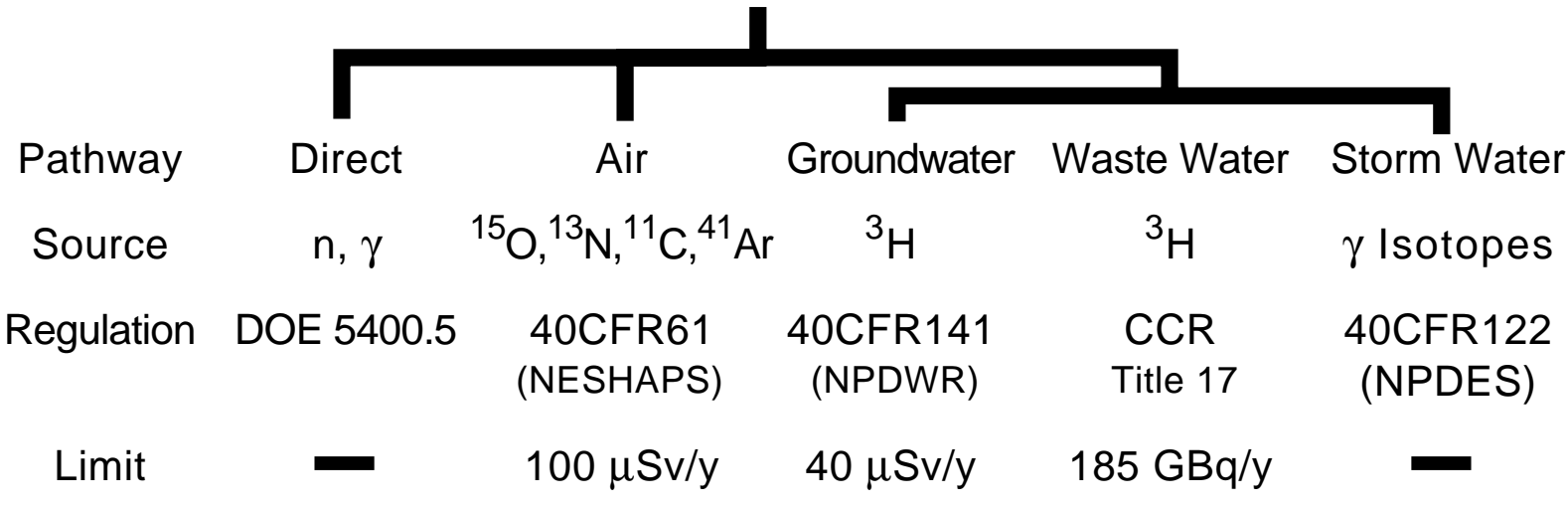

Figure 1. Environmental radiological protection scheme at Stanford Linear Accelerator Center.

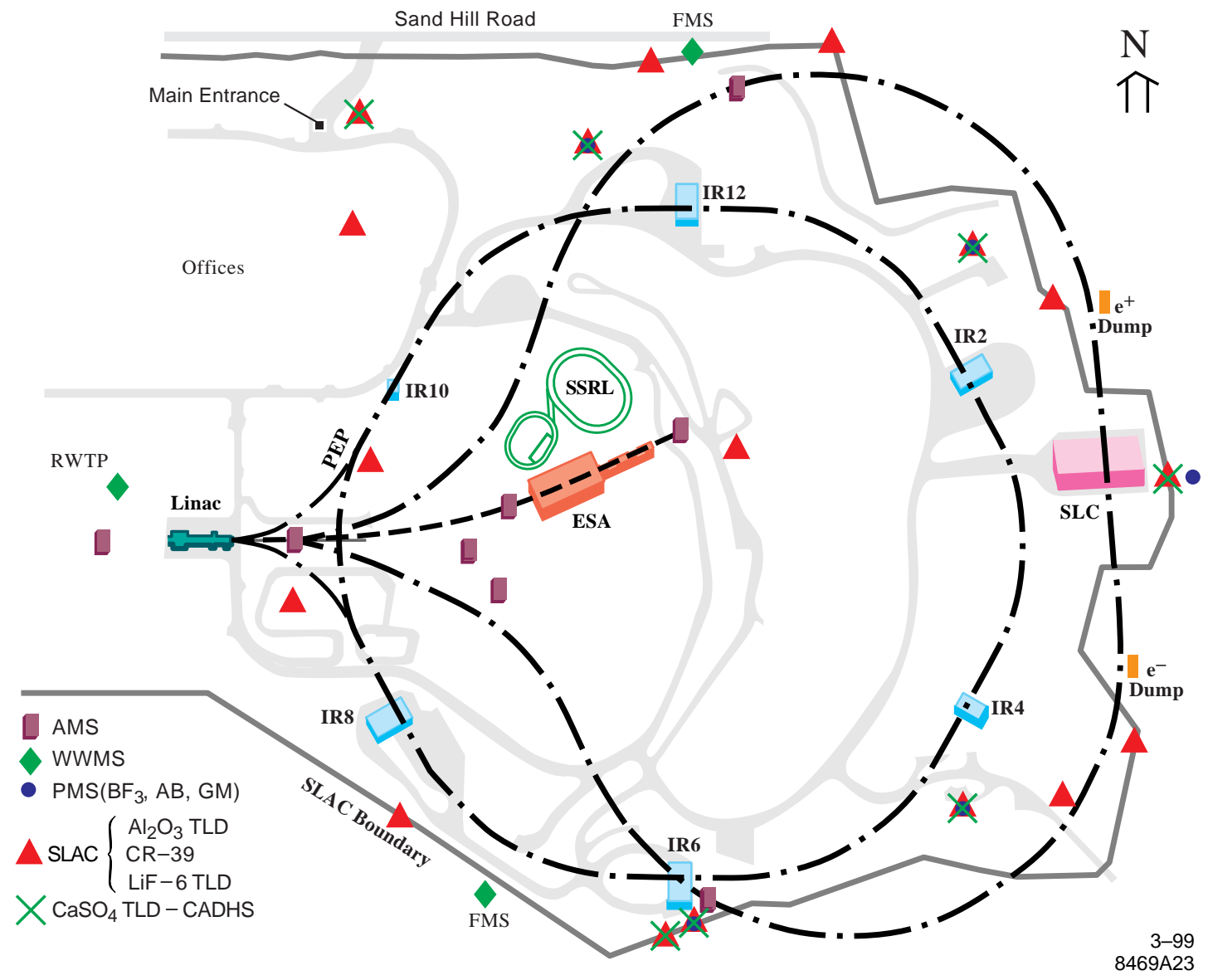

Figure 2. SLAC accelerator facilities and radiological monitoring plans. 


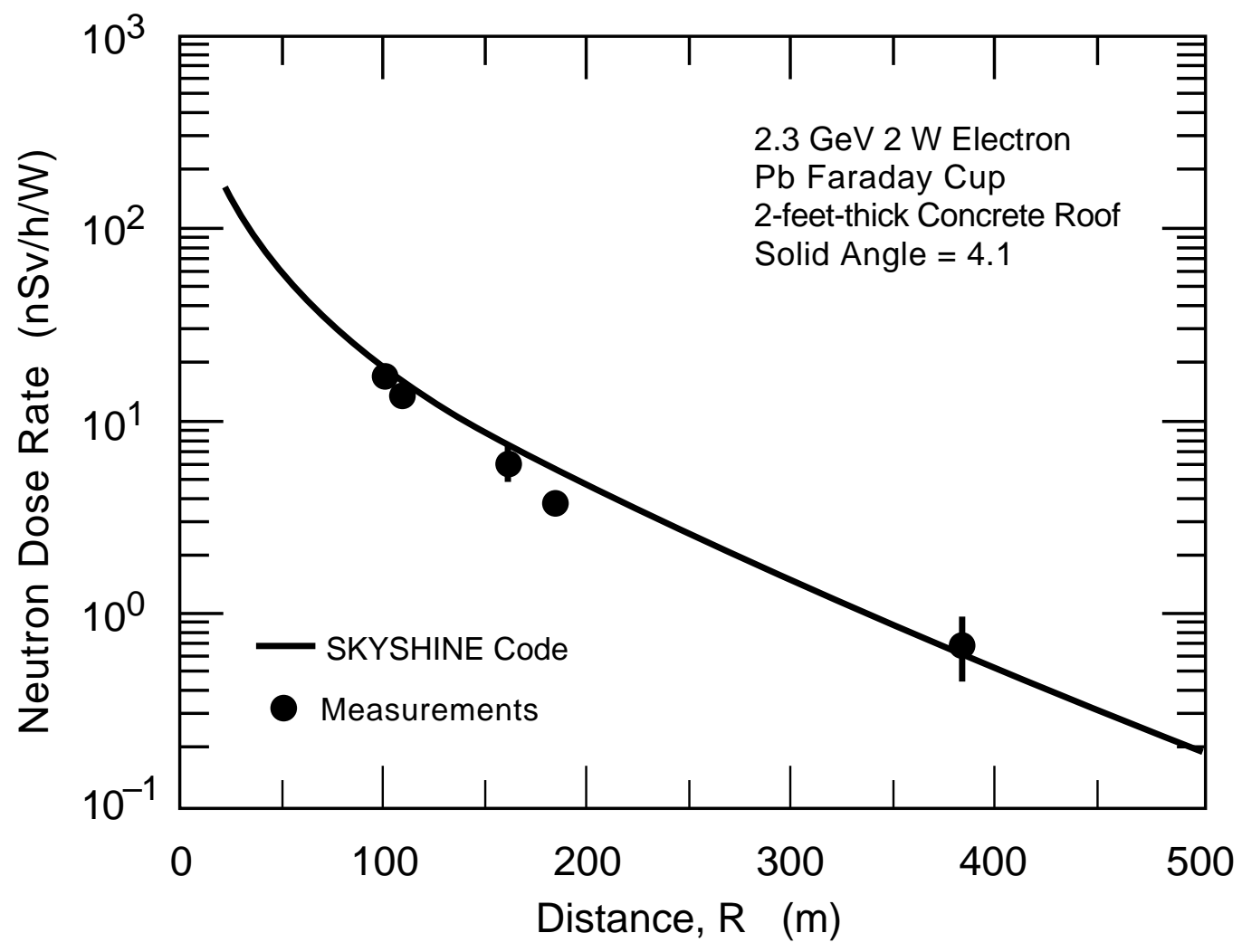

Figure 3. Neutron skyshine from SSRL beam parked in Faraday cup.

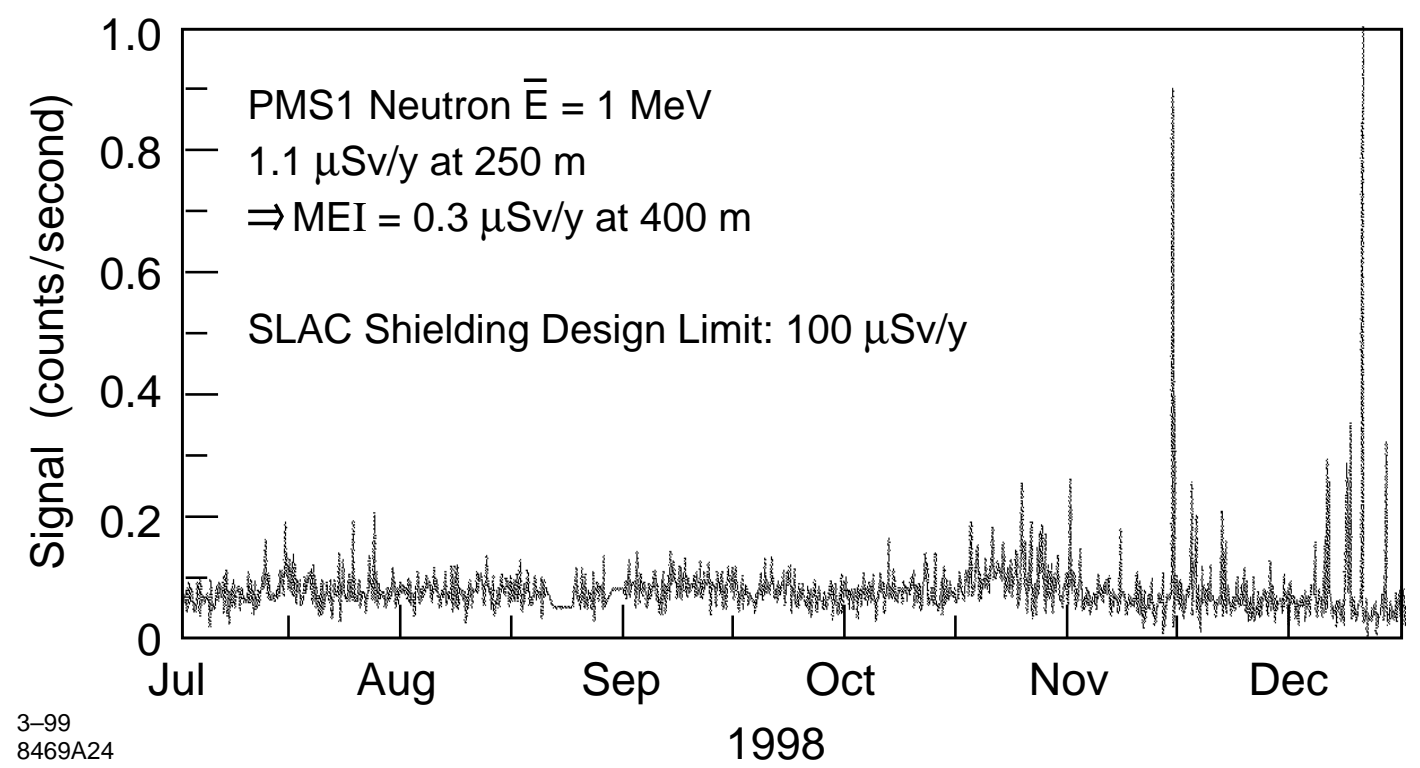

Figure 4. Skyshine neutrons at SLAC boundary from SSRL operation. 


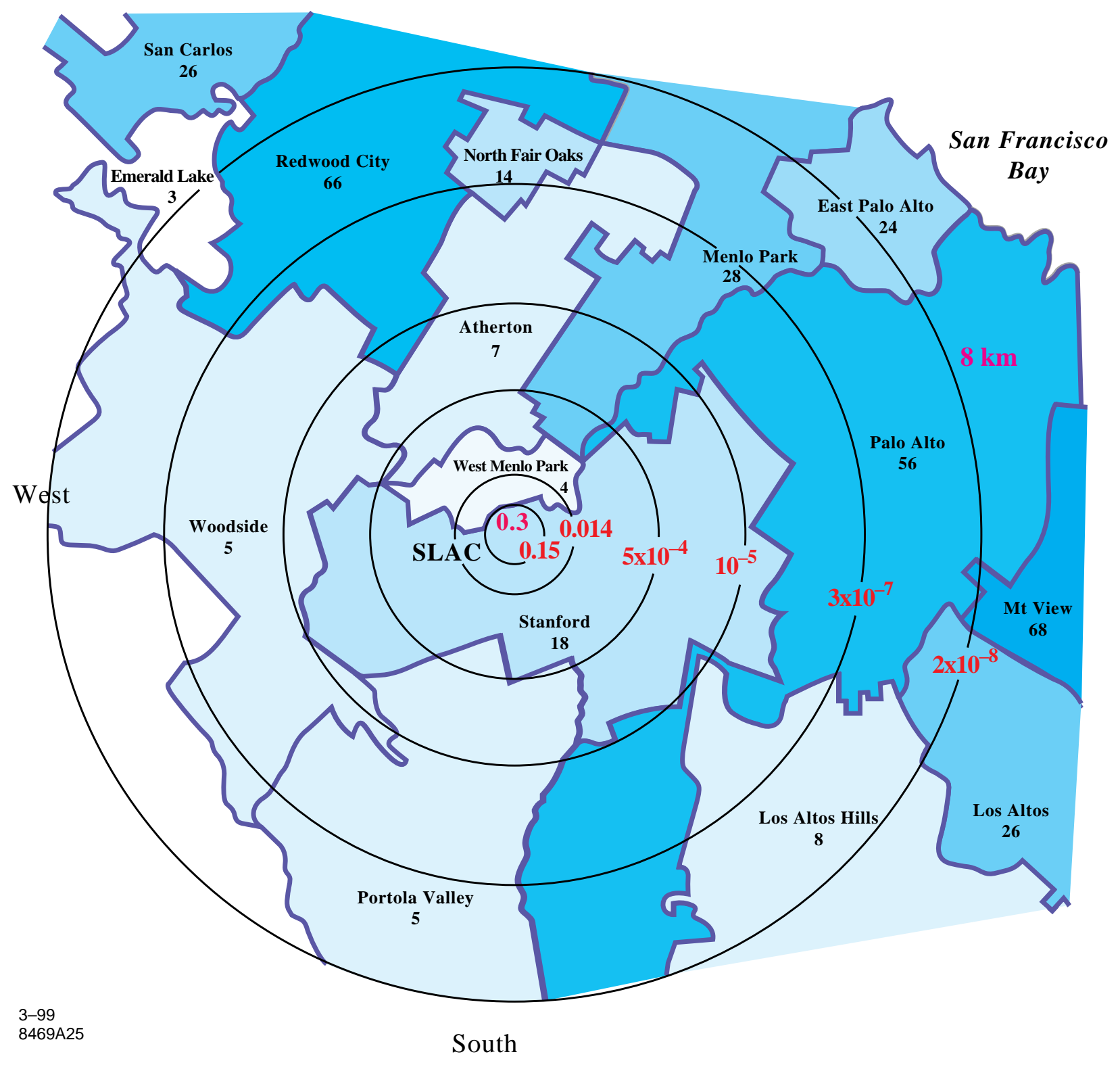

Figure 5. Off-site doses ( $\mu \mathrm{Sv} / \mathrm{y}$ ) up to $8 \mathrm{~km}$ away from SLAC due to SSRL skyshine neutrons (the numbers under the city names are the population in thousands). 


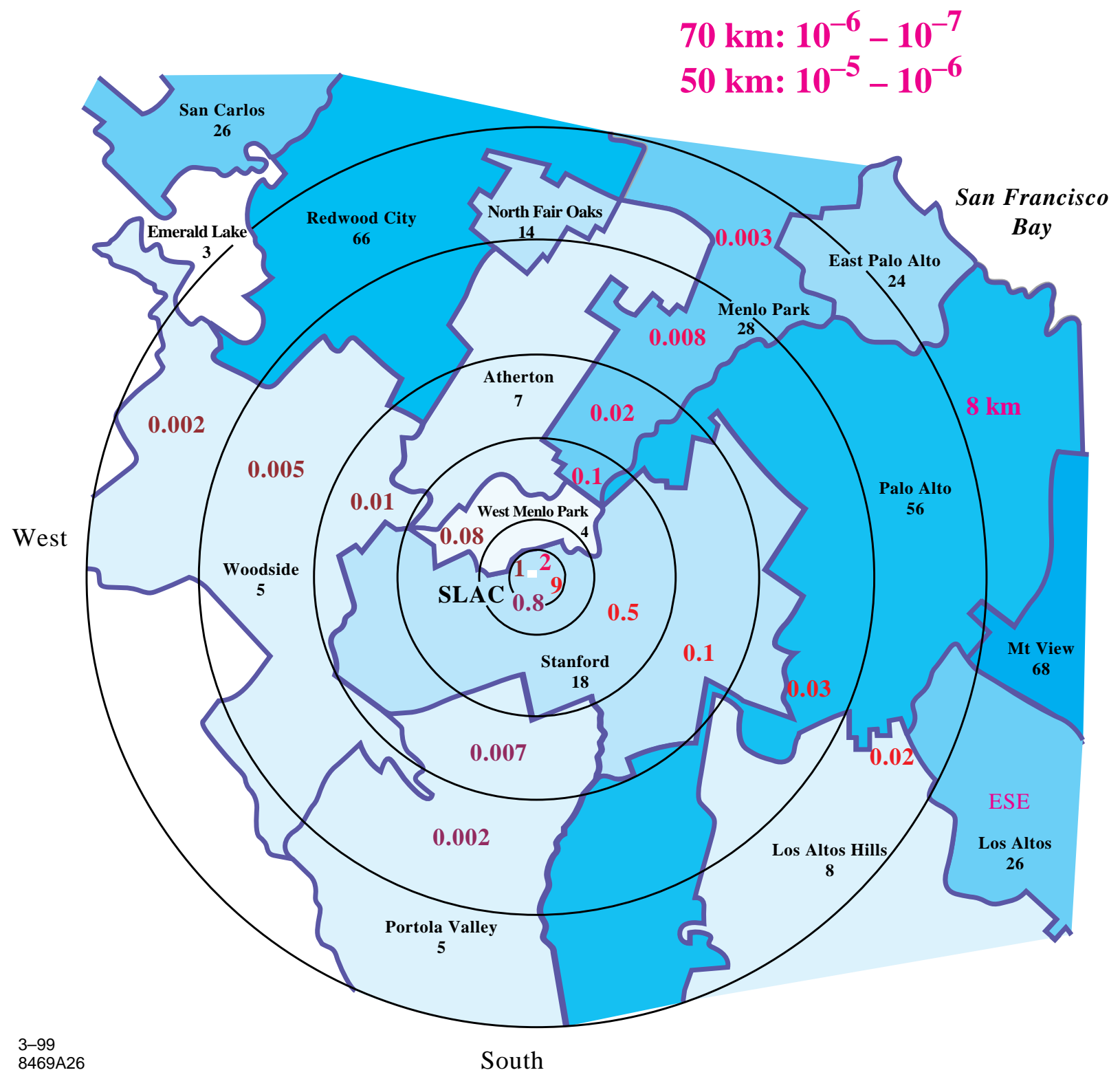

Figure 6. Off-site doses $(\mu \mathrm{Sv} / \mathrm{y})$ from radioactive air release due to PEP-II operation, calculated using CAP88. 


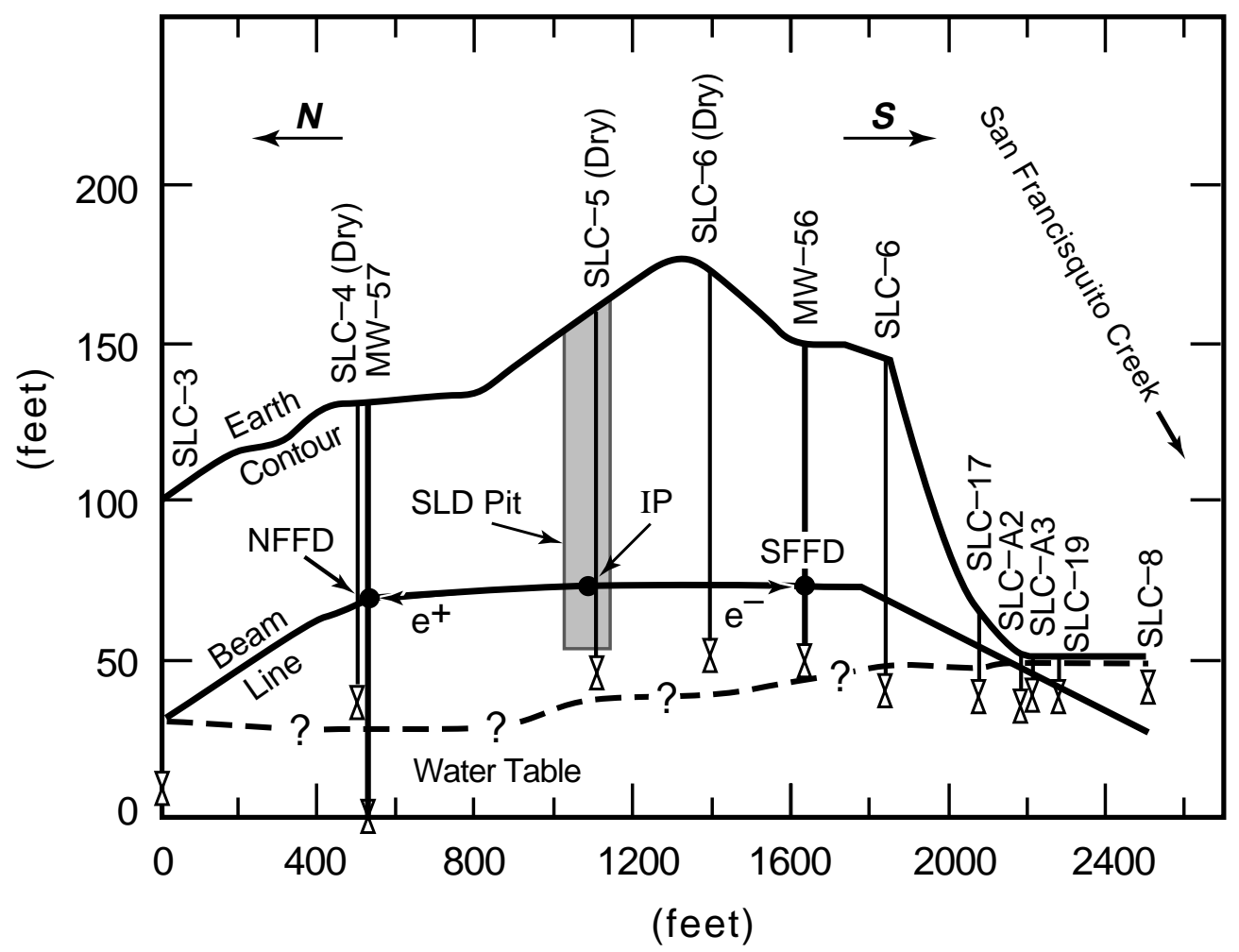

Figure 7. North-south cut along the SLC beam line passing through the interaction point (IP). $50 \mathrm{~kW}$ beams are parked continuously on the dumps.

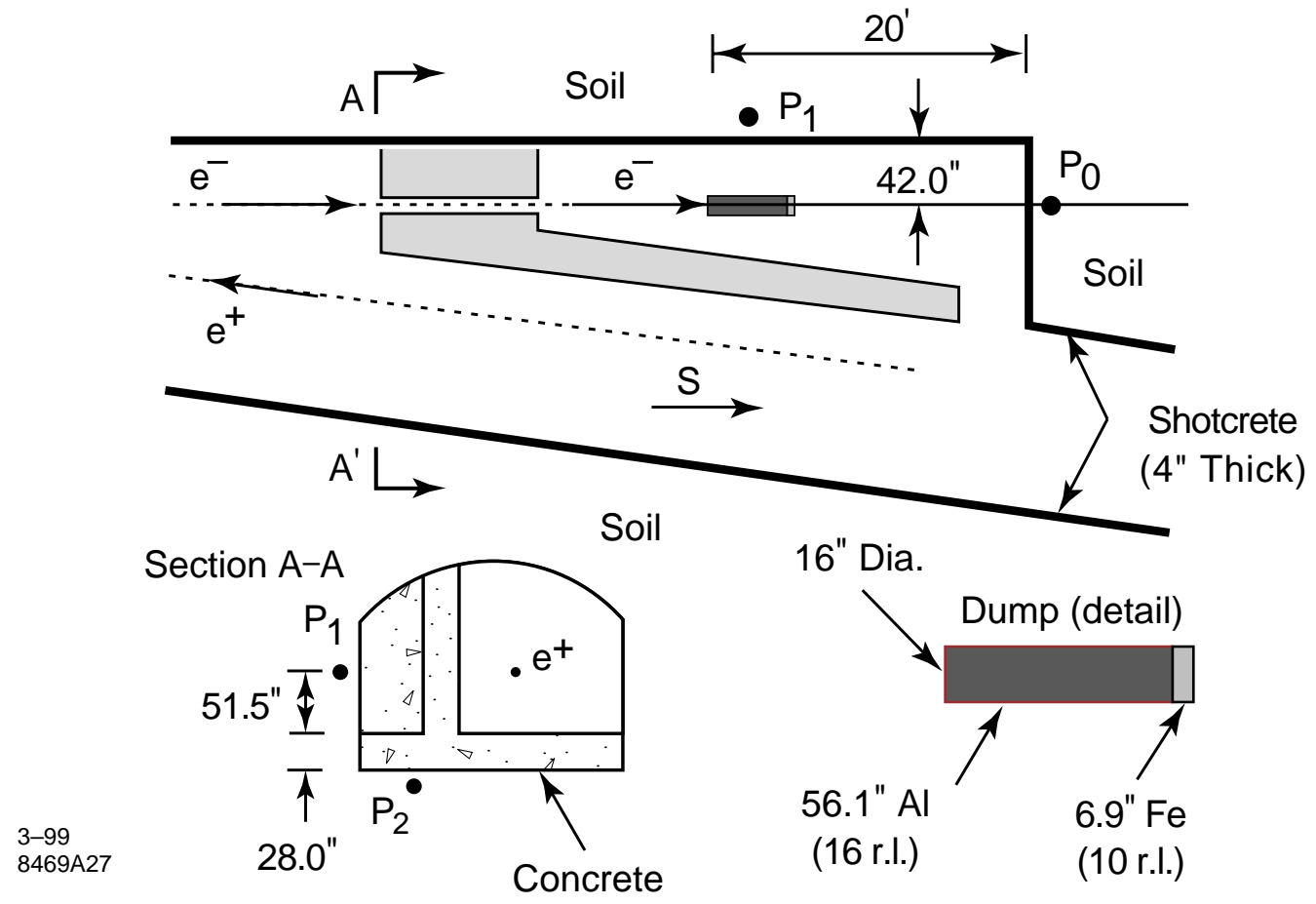

Figure 8. Layout of the south final focus dump 